\title{
Effect of reaction mode on biohydrogen production and its microbial diversity
}

\author{
Buchun Si ${ }^{\mathrm{a}}$, Zhidan Liu ${ }^{\mathrm{a},}$, Yuanhui Zhang ${ }^{\mathrm{a}, \mathrm{c}}$, Jiaming $\mathrm{Li}^{\mathrm{a}}$, Xin-Hui Xing ${ }^{\mathrm{b}}$, \\ Baoming $\mathrm{Li}^{\mathrm{a}}$, Na Duana, Haifeng $\mathrm{Lu}^{\mathrm{a}}$ \\ ${ }^{a}$ Laboratory of Environment-Enhancing Energy (E2E), and Key Laboratory of Agricultural \\ Engineering in Structure and Environment, Ministry of Agriculture, College of Water Resources \\ and Civil Engineering, China Agricultural University, Beijing, 10083, China \\ ${ }^{\mathrm{b}}$ Department of Chemical Engineering, Tsinghua University, 100084, Beijing, China \\ ${ }^{c}$ Department of Agricultural and Biological Engineering, University of Illinois at Urbana-
}

Champaign, Illinois, 61801, USA

* Corresponding author.

Tel.:+086-010-6273-7329, Fax: +086-010-6273-7329

E-mail address: zdliu@cau.edu.cn (Z.Liu). 


\begin{abstract}
Biohydrogen production using the high-rate reactor is promising due to its ability of maintaining higher biomass concentrations through forming granules or biofilms. This study investigated the effect of reaction mode on hydrogen fermentation by comparing an upflow anaerobic sludge blanket (UASB) and a packed bed reactor (PBR). UASB and PBR were operated for 120 days at hydraulic retention time (HRT) of 24-12 h and organic loading rates (OLRs) of 0.96-15.36 g COD/L/d. Both UASB and PBR achieved maximal hydrogen production rates as $2.77 \pm 0.18$ and $1.28 \pm 0.12 \mathrm{~L} / \mathrm{L} / \mathrm{d}$, respectively, at $15.36 \mathrm{~g} \mathrm{COD} / \mathrm{L} / \mathrm{d}$, corresponding to hydrogen yields of $1.44 \pm 0.01$ and $0.67 \pm 0.06$ $\mathrm{mol} / \mathrm{mol}$ glucose. Illumina MiSeq sequencing results revealed Clostridium sp. was the dominant microbial consortium for hydrogen production in UASB $(92.1 \%)$ and PBR (71.7\%). Compared to UASB, PBR showed a greater microbial diversity of ethanol and lactic acid producers, and may be more favorable for methanogenesis and homoacetogenesis. This study demonstrates that reaction mode significantly influenced microbial diversity and biohydrogen production.
\end{abstract}

Keywords: Biohydrogen production, Microbial diversity, Packed bed reactor, Reaction mode, Upflow anaerobic sludge blanket

\title{
1. Introduction
}

Hydrogen is a promising energy due to its rapid burning speed, high octane number, outstanding combustion efficiency and high energy content [1]. Currently, the overwhelming majority of hydrogen production comes from fossil fuels [2]. Biohydrogen 
production through dark fermentation is promising due to the faster process and no direct requirement of solar energy [3].

Compared with conventional continuous stirred tank reactor (CSTR), the high-rate reaction mode has been recommended as a promising alternative for biohydrogen production from wastewater due to its ability of maintaining higher biomass concentrations by forming granules or biofilms [4]. Upflow anaerobic sludge blanket (UASB) which can form granules, has been widely used for biohydrogen production at high treatment efficiency and short hydraulic retention time (HRT) of 2-24 h with hydrogen yields of $0.75-2.57 \mathrm{~mol} / \mathrm{mol}$ hexose [5-9]. Similarly, a packed bed reactor (PBR) can enhance hydrogen fermentation by forming biofilms on the packed materials at short HRT $(0.5-24 \mathrm{~h})$ and high organic loading rate (OLR) of 6.5-960 g COD/L/d with hydrogen yield of $0.35-2.11 \mathrm{~mol} / \mathrm{mol}$ hexose [10-15]. Efficient hydrogen producing microbes were enriched using high-rate bioreactors. Clostridium, Enterobacter, Ruminococcus, Klebsiella, Pantoea, Caloramator were found in granules in UASB [7-9]. In comparison, the biofilm formed in PBR had a broader microbial diversity including Clostridium, Ruminococcus, Enterobacter, Lactobacillus, Streptococcus, Pseudomonas, Klebsiella, Propionispira, Klebsiell [11-14]. In addition, hydrogen production through PBR was reported unstable due to the existence of homoacetogenic organisms, such as Clostridium ljungdahlii $[15,16]$. Lee et al. reported that hydrogen production in granules or biofilms system was related to the diversity of Clostridia [17]. Efforts have been made to compare the biofilm and granules system. Zhang et al. compared biofilm and granular system for biohydrogen production in two anaerobic fluidized bed reactors, and the hydrogen yields obtained in both reactors ranged from 0.4 to $1.7 \mathrm{~mol} \mathrm{H}_{2} /$ mol glucose [18]. Alzate-Gaviria et al. studied the hydrogen production of the PBR and UASB fed with 
organic fraction of municipal solid waste (OFMSW) and synthetic wastewater, respectively. The UASB and PBR achieved $30 \%$ and $23 \%$ of the maximum hydrogen yield (4 mol $\mathrm{H}_{2} / \mathrm{mol}$ glucose) [19]. However, the hydrogen production and microbial diversity in two reaction modes (UASB and PBR) under similar operational conditions have not been systemically compared.

The aim of the study was to investigate the effect of reaction mode on biohydrogen production through comparing the difference between the two typical high-rate reactors (UASB and PBR) under the same operational conditions including the feedstock, OLR, temperature and initial $\mathrm{pH}$. In addition, the influence of reaction mode on microbial diversity and functions during hydrogen fermentation was examined and discussed.

\section{Methods}

\subsection{Inoculum}

The inoculum was obtained from an anaerobic digester at the Xiaohongmen Municipal Sewage Treatment Plant (Beijing, China). The volatile suspended solids (VSS) concentration and total suspended solids (TSS) concentration of the seed sludge were 8.12 and $24.7 \mathrm{~g} / \mathrm{L}$, respectively. The sludge was boiled at $100^{\circ} \mathrm{C}$ for $15 \mathrm{~min}$ to inhibit methanogenesis activity and harvest anaerobic spore-forming bacteria prior to use [20].

\subsection{Substrate}

Glucose and $\mathrm{NH}_{4} \mathrm{Cl}$ were used as carbon and nitrogen sources to mimic the carbohydraterich wastewater with a carbon/nitrogen ratio of 47 based on nutrients requirement [21]. The concentrations of glucose and $\mathrm{NH}_{4} \mathrm{Cl}$ were then altered to reach desired OLRs, and sodium bicarbonate was added (1 g/g COD) as a buffer. Besides these compositions, the 
substrate contained (mg/L): $\mathrm{K}_{2} \mathrm{HPO}_{4} 250, \mathrm{KH}_{2} \mathrm{PO}_{4} 250, \mathrm{MgCl}_{2} 300, \mathrm{CoCl}_{2} 25, \mathrm{ZnCl}_{2} 11.5$, $\mathrm{CuCl}_{2} 10.5, \mathrm{CaCl}_{2} 5, \mathrm{MnCl}_{2} 15, \mathrm{NiSO}_{4} 16, \mathrm{FeCl}_{3} 25$ [22]. The initial $\mathrm{pH}$ of substrate was controlled in a desired interval (5-6.5), depending on the reactor performance.

\subsection{Reactor design and experimental procedure}

Fig 1 shows the schematic setup of the lab-scale high-rate reactors (UASB and PBR). The two reactors were made from transparent acrylic and both had a working volume of $2.5 \mathrm{~L}$, and a height to diameter ratio of $6: 1$. To enhance the microbial retention and accelerate the enrichment, the CNTs at $100 \mathrm{mg} / \mathrm{L}$ were added into the UASB as the microbial carrier [8], whereas polyethylene rings $(1 \mathrm{~cm}$ diameter and $1 \mathrm{~cm}$ wide) at $175 \mathrm{~g} / \mathrm{L}$ were packed to the PBR with the void space ratio of $80 \%$. Reactors were maintained at $37^{\circ} \mathrm{C}$ using water bath recirculation. Heat-treated anaerobic sludge was used as the inoculum at a volume ratio of 1:4. The reactors were flushed with nitrogen gas at $100 \mathrm{~mL} / \mathrm{min}$ for $30 \mathrm{~min}$ to remove dissolved $\mathrm{O}_{2}$ and obtain anaerobic conditions. The reactors were operated at OLRs of 0.96$15.36 \mathrm{~g} \mathrm{COD} / \mathrm{L} / \mathrm{d}$ through changing the HRT and initial concentration of the substrate. Steady-state conditions were defined as the variations of hydrogen production rate and hydrogen concentration were constant $( \pm 10 \%)$ during 6 HRT of operation.

\subsection{Analytical methods}

Gas production was measured using a gas meter. Gas compositions were determined by a gas chromatographer (GC1490, Agilent Technologies, USA) equipped with a thermal conductivity detector (TCD) and a stainless steel column packed with TDX-01. Measured gas compositions included hydrogen, methane and carbon dioxide. The temperatures in the injector, column and detector were 150,120 and $150^{\circ} \mathrm{C}$, respectively. The nitrogen gas was 
used as the carrying gas at a flow rate of $50 \mathrm{~mL} / \mathrm{min}$. Gas compositions, volume and $\mathrm{pH}$ of the effluents were monitored every day.

The volatile fatty acids (VFAs) produced during hydrogen fermentation were analyzed using a high performance liquid chromatography (HPLC) (Shimadzu, Japan) equipped with an ultraviolet detector and an acid analysis column (Phenomenex, USA). 5 $\mathrm{mM} \mathrm{H}_{2} \mathrm{SO}_{4}$ was used as mobile phase at a flow rate of $1 \mathrm{~mL} / \mathrm{min}$. The oven temperature was $40^{\circ} \mathrm{C}$. Samples were centrifuged $(4000 \mathrm{rpm}, 10 \mathrm{~min})$ and the supernatant was filtered using a 0.45 um membrane filter before use. Chemical oxygen demand (COD) was measured according to standard methods [23].

After 120 days of operation (HRT 12 h, OLR 15.36g COD/L/d), hydrogen-producing granules in UASB and microbial carriers with hydrogen-producing biofilm in PBR were sampled. The microbial samples were then stored at $-20^{\circ} \mathrm{C}$ prior to analysis together with inoculum. The microbial morphology was observed by scanning electron microscopy (Quanta 200, FEI, USA) as previously described [8].

The phylogenetic diversity of the microbial consortium was analyzed via Illumina MiSeq sequencing [24]. Genomic DNA was first extracted from microbial samples using the E.Z.N.A DNA Isolation Kit (Omega Biotec, USA). The V4-V5 regions of the bacteria 16S ribosomal RNA gene were then amplified by GeneAmp PCR System (ABI company, USA) using primers 515F (5'-barcode-GTGCCAGCMGCCGCGG-3') and 907R (5'CCGTCAATTCMTTTRAGTTT-3'), where the barcode was an eight-base sequence unique to each sample. The PCR process was conducted as follows: $95^{\circ} \mathrm{C}$ for 2 min, followed by 25 cycles at $95^{\circ} \mathrm{C}$ for $30 \mathrm{~s}, 55^{\circ} \mathrm{C}$ for $30 \mathrm{~s}, 72^{\circ} \mathrm{C}$ for $30 \mathrm{~s}$ and a final extension at $72^{\circ} \mathrm{C}$ for $5 \mathrm{~min}$. PCR reactions were performed in triplicate. Each $20 \mu \mathrm{L}$ PCR reaction mixture contained $4 \mu \mathrm{L}$ of $5 \times$ FastPfu Buffer, $2 \mu \mathrm{L}$ of $2.5 \mathrm{mM}$ dNTPs, $0.8 \mu \mathrm{L}$ of each 
primer $(5 \mu \mathrm{M}), 0.4 \mu \mathrm{L}$ of FastPfu Polymerase, and $10 \mathrm{ng}$ of template DNA. Amplicons were extracted from 2\% agarose gels, purified using the AxyPrep DNA gel extraction kit (Axygen Biosciences, USA) and quantified using QuantiFluor ST (Promega, USA). Purified amplicons were pooled in equimolar and paired-end sequenced on an Illumina MiSeq platform. Finally, the raw reads were deposited into the National Center for Biotechnology Information (NCBI) Sequence Read Archive (SRA) database. Raw fastq files were demultiplexed and quality-filtered using Quantitative Insights into Microbial Ecology (QIIME). Reads which could not be assembled were discarded. Operational Taxonomic Units (OTUs) were clustered with 97\% similarity cutoff using UPARSE (version $7.1 \mathrm{http}: / /$ drive5.com/uparse/) and chimeric sequences were identified and removed using UCHIME. The phylogenetic affiliation of each 16S rRNA gene sequence was analyzed by RDP Classifier (http://rdp.cme.msu.edu/) against the silva (SSU115) 16S rRNA database using confidence threshold of $70 \%$.

\subsection{Calculations of hydrogen fermentation}

Hydrogen production was also calculated based on the biochemical reactions in order to better reveal the distribution of hydrogen. The theoretical biohydrogen production $\left(\mathrm{H}_{2}\right.$ theoretical, $\mathrm{mM}$ ) was calculated [25]:

$$
\mathrm{H}_{2 \text { theoretical }}=2 \mathrm{M}_{\mathrm{But}}+2 \mathrm{M}_{\mathrm{Ac}}-\mathrm{M}_{\text {Prop }}
$$

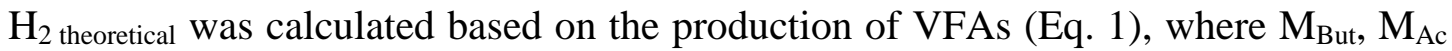
and $\mathrm{M}_{\text {Prop }}$ represented the concentrations of butyric acid, acetic acid, and propionic acid $(\mathrm{mM})$, respectively. Note that other products, including lactic acid and ethanol were not considered as previously described [25]. The activity of homoacetogenesis and methane production by hydrogenotrophic methanogens should be considered: 


$$
\begin{aligned}
& \mathrm{H}_{2 \text { homo }}=4 \mathrm{M}_{\mathrm{Achomo}} \\
& \mathrm{H}_{2 \text { methane }}=4 \mathrm{CH}_{4 \text { measured }}
\end{aligned}
$$

Where $\mathrm{H}_{2}$ methane and $\mathrm{H}_{2}$ homo represented the hydrogen consumed by hydrogenotrophic methanogen and homoacetogenesis in $\mathrm{mM}$, respectively, and $\mathrm{M}_{\mathrm{Ac} \text { homo }}$ and $\mathrm{CH}_{4}$ measured represented the acetic acid $(\mathrm{mM})$ produced by homoacetogenesis and $\mathrm{CH}_{4}(\mathrm{mM})$ produced by hydrogenotrophic methanogens, respectively. Based on the above equation, $\mathrm{M}_{\mathrm{Ac}}$ homo can be calculated [26]:

$$
\mathrm{M}_{\mathrm{Ac} \mathrm{homo}}=\left(2 \mathrm{M}_{\mathrm{But}}+2 \mathrm{M}_{\mathrm{Ac}}-\mathrm{M}_{\text {Prop }}-\mathrm{H}_{2 \text { measured }}-4 \mathrm{CH}_{4 \text { measured }}\right) / 6
$$

Where $\mathrm{H}_{2}$ measured represented the actually measured hydrogen (mM).

\section{Results and discussion}

\subsection{Performance of UASB and PBR for biohydrogen production}

\subsubsection{Biohydrogen production}

Fig. 2 showed the comparison of UASB and PBR for biohydrogen production. The HRT was set as $24 \mathrm{~h}$ in the first $37 \mathrm{~d}$ and then reduced to $12 \mathrm{~h}$ to avoid the risk of microorganisms washing-out. It was clear that the initial $\mathrm{pH}$ and concentration of substrate had an effect on the hydrogen production and composition [27]. The reported optimum initial $\mathrm{pH}$ values for hydrogen production ranged from 5 to 6.5 [28]. In this study, the initial $\mathrm{pH}$ was adjusted to 5.5 and 6.5 in the first $22 \mathrm{~d}$, while significant methane production was observed (Fig. 2E). As a result, the initial $\mathrm{pH}$ was set as 5 at OLR of 0.96, 1.92 and $3.84 \mathrm{~g} \mathrm{COD} / \mathrm{L} / \mathrm{L}$, and then changed to 5.5 at OLR of 7.68 and $15.36 \mathrm{~g} \mathrm{COD} / \mathrm{L} / \mathrm{L}$ to suppress methane production. As showed in Fig. 2, both UASB and PBR had a low hydrogen production in the first $56 \mathrm{~d}$ at OLRs of $0.96 \mathrm{~g}$ and $1.92 \mathrm{~g} \mathrm{COD} / \mathrm{L} / \mathrm{d}$. This suggested that low ORL was not desirable for the startup of hydrogen fermentation. With 
the initial concentration increased to $1.92 \mathrm{~g} \mathrm{COD} / \mathrm{L}$, corresponding to an OLR of $3.84 \mathrm{~g}$ COD/L/d, UASB and PBR achieved a steady hydrogen composition and a constant hydrogen production rate at 79 and 81 d, respectively. Fig. 2 revealed that reaction mode influenced the gas composition and gas production rate. Less than $1 \%$ methane content with a methane production rate (MPR) of $0.01-0.04 \mathrm{~L} / \mathrm{L} / \mathrm{d}$ was observed in UASB at the steady state. In comparison, the methane production in PBR was more significant (>12\%) with a higher MPR of 0.04-0.49 L/L/d, which is consistent with the findings by Penteado et al.[29]. The hydrogen contents in UASB (47.5-54.7\%) were higher than those in PBR (26.4-34.0\%) at the steady-states after each OLR, corresponding to hydrogen production rate in UASB (0.22-2.77 L/L/d) and PBR (0.50-1.28 L/L/d). Alzate-Gaviria et al. also found the UASB and PBR systems had different performance of hydrogen production [19]. The better hydrogen production in UASB may partially result from the mass transfer. Another study compared hydrogen production using biofilm and granular sludge system in two anaerobic fluidized bed reactors [18]. However, no significant difference was observed, probably due to the similar mass transfer in two fluidized bed reactors. In this study the limited mass transfer in PBR made hydrogen difficult to release from packed carriers. The increase of hydrogen partial pressure would inhibit the hydrogen production and may limit the use of higher feeding strengths $[4,30]$. Hence, a short HRT or backmixing might be required for the PBR in order to strengthen the mass transfer $[4,16]$. Compared to PBR, UASB had a better mass transfer for the effective contact between the microbial consortia and the substrate. Besides these, the three phase separator used in UASB made the biogas easy to release, and decreased the hydrogen partial pressure, therefore leading to a higher total gas and hydrogen production. ORL had an influence on the hydrogen yield. The yields of hydrogen in UASB increased from $4 \pm 6 \mathrm{mmol} / \mathrm{mol}$ to 
$1.44 \pm 0.01 \mathrm{~mol} / \mathrm{mol}$ glucose (Fig. 3), with the increase of the OLR from 0.96 to $15.36 \mathrm{~g}$ COD/L/d. The PBR exhibited a similar trend with an increase in hydrogen yields from $6 \pm$ $22 \mathrm{mmol} / \mathrm{mol}$ to $0.67 \pm 0.06 \mathrm{~mol} / \mathrm{mol}$ glucose with the increase of OLR. The results suggested increasing OLR may be an appropriate way to enrich hydrogen-producing bacteria. However, the methanogenesis was not effectively suppressed as methane yields in the PBR increased from $5 \pm 8 \mathrm{mmol} / \mathrm{mol}$ to $0.26 \pm 0.01 \mathrm{~mol} / \mathrm{mol}$ glucose. The significant methanogenesis in PBR may be caused by the active hydrogenotrophic methanogens to consume the produced hydrogen.

\subsubsection{Variation of VFAs concentrations and COD removal rate}

Acetic acid, lactic acid and butyric acid are the common metabolites and main VFAs during the hydrogen production (Fig. 2H, I). The different distribution of metabolism products in two reactors revealed different metabolic pathways caused by different microbial communities. As showed in Fig. 2H and Fig. 2I, the yields of acetic acid were $0.51 \pm 0.06,0.57 \pm 0.09$ and $0.47 \pm 0.08 \mathrm{~mol} / \mathrm{mol}$ glucose at the steady state of $3.84,7.68$, 15.36 $\mathrm{g} \mathrm{COD/L/d} \mathrm{in} \mathrm{PBR,} \mathrm{respectively.} \mathrm{In} \mathrm{comparison,} \mathrm{the} \mathrm{yields} \mathrm{of} \mathrm{acetic} \mathrm{acid} \mathrm{in} \mathrm{UASB}$ were much lower as $0.27 \pm 0.08,0.34 \pm 0.04$ and $0.29 \pm 0.01 \mathrm{~mol} / \mathrm{mol}$ glucose, respectively. The difference may be caused by homoacetogenesis, which would convert hydrogen and carbon dioxide into acetic acid [16].

COD removal rate was around $20 \%$ for both reactors during the steady-state process (Fig. 2G), similar to the previous study $(19.2-38.8 \%)[15,31,32]$. Specifically, the COD removal rates of PBR $(22.2 \pm 2.4 \%)$ and UASB $(22.0 \pm 3.7 \%)$ were similar at an OLR 15.36g COD/L/d although the significant difference in methane production in UASB and PBR was obtained. The conflict may be because the methane production were mainly 
conducted by hydrogenotrophic methanogens, as aceticlastic methanogens will increase the COD removal rate through converting acetic acid into methane and carbon dioxide.

\subsection{Microbial morphology and diversity in UASB and PBR}

Fig.4 showed the SEM images of the inoculum, granules in UASB and biofilm in PBR. The inoculum originally consisted of flocculent and dispersed microbial community (Fig. 4A, D). The mature hydrogen-producing granules were observed covered with cracks in UASB after 120 d's operation (Fig. 4B). These granules were primarily rod shape bacteria, which bounded with each other tightly as shown in Fig. 4E. A small amount of coccusshaped bacteria were also observed. Inner porous structure of the granules was observed. In comparison, biofilms were formed on the polyethylene carrier in PBR (Fig. 4C). More microbial communities with broader diversity were observed on the biofilm, where microbial consortia were connected each other through extracellular secretions (Fig. 4F).

Illumina MiSeq sequencing results revealed the significant difference of microbial diversity in inoculum, UASB and PBR (Table 1). As showed in the Table 1, Ace and Chao indexes indicate the richness of the microbial communities, whereas Shannon and Simpson indexes represent the microbial diversity [33]. Of the three samples, the inoculum had the highest indexes of Shannon, ACE and Chao, and the lowest Simpson index, indicating the biggest bacterial species diversity and highest species richness of the three samples. This suggested that the specific microbes in UASB and PBR had been selectively enriched through the long term operation. Compared to UASB, PBR had higher species richness and bigger of microbial diversity. Fig.5 illustrated the relationship of microbial diversity among the three communities. The sum of total observed OTUs in the inoculum (373), UASB (45) and PBR (93) were in accord with their richness. The overlap between UASB 
(31, 69\%) and PBR $(31,30 \%)$ showed a strong similarity of microbial diversity between them. The extra unique parts of UASB and PBR may be owing to the limitation of sample detection, included in the unclassified part in inoculum (13\%). Although only 7 OTUs were shared by three of them, the majority microbial species in UASB (92\%) and PBR (76\%) were included. The OTUs ratios of UASB/inoculum (12\%) and PBR/inoculum (25\%) were proposed to represent the effect of specific microbe enrichment in the reactors. It is clear that the two reaction mode had different biomass enrichment process. Compared to UASB, PBR may have a stronger ability to retain the microbial consortia, owing to its high speed of incubating the biofilm attached on the carrier in the early operational stage $[10,34]$. Moreover, the biofilm system were more resistant to process imbalances [35-37] could favor the slow growing of microorganisms. This would have a negative effect on eliminating the methanogens. The current study confirmed the significant activity of methanogens in PBR under high OLR and short HRT (Fig.2E). In comparison, the formation of active microbial consortia enriched in UASB through anaerobic sludge granulation required a relatively long time (2-8 months) [38]. Chang and Lin observed visible granules after 4 months in UASB for biohydrogen production [6]. The granulation process is a selective evolution of the microbial community [9, 39], and hence methanogens were easily washed out under specific operation conditions such as short HRT and low initial $\mathrm{pH}$.

Fig. 6 detailed the microbial diversity at the levels of phyla, families and genera. The inoculum had the highest diversity with 25 identified phyla. The main phyla were Bacteroidetes (7.4\%), Chloroflexi (23.2\%), Proteobacteria (20.4\%) and Spirochaetae (31.5\%), and the phylum Firmicutes only accounted for $2.5 \%$. Compared to the inoculum, UASB and PBR exhibited much simple microbial consortium with only 6 and 7 identified 
phyla, indicating a selection process occurred for each reactor system. The significant difference between UASB and PBR was the distribution of phyla Bacteroidetes, Firmicutes and Proteobacteria (Fig. 6A). The phylum Firmicutes was the main microbial consortium in UASB (99.7\%) and PBR (91.4\%). PBR had a higher richness than UASB, including Bacteroidetes (0.2\%), Proteobacteria (2.9\%) and unclassified (5.3\%). Further analysis at the families level showed that the phylum Firmicutes in UASB and PBR consisted of Clostridiaceae, Leuconostocaceae, Streptococcaceae and Ruminococcaceae (Fig 6B). Among these, Clostridiaceae was the dominant family in UASB (93.3\%) and PBR (73.4\%). The relative abundance of families Leuconostocaceae, Ruminococcaceae, Streptococcaceae, Enterobacteriaceae in PBR was higher than that in UASB. From the perspective of genus (Fig 6C), Clostridium sp. was found as the main genus in PBR (71.7\%) and UASB (92.1\%) which was regarded as the most common microbial consortium in biohydrogen fermentation $[9,13,17,40]$. As showed in the Table 2, butyrate and acetate were reported as the primary soluble metabolites produced by Clostridium sp. for hydrogen fermentation [41]. In particular, Ethanoligenens sp. and Ruminococcaceae Incertae Sedis sp., which belong to family Ruminococcaceae were found in both reactors. Ethanol was also produced although Ruminococcaceae were hydrogen producers [42]. Guo et al. reported Ethanoligenens harbinense B49 from the family Ruminococcaceae was an effective hydrogen producer by ethanol type fermentation [43]. Weissella sp. and Lactococcu sp. were also identified, which belong to lactic acidproducing family Leuconostocaceae and Streptococcaceae, respectively [44, 45]. Leuconostocaceae were found in the biofilm of PBR by Chojnacka et al. [46], Leuconostocaceae are heterofermentative bacteria able to produce lactic acid, acetic acid, and ethanol [46], whereas Streptococcaceae are facultatively anaerobic bacteria able to 
produce lactic acid by fermentation [47]. The higher relative abundance of Ruminococcaceae Incertae Sedis sp., Ethanoligenens sp., Weissella sp., and Lactococcu sp. in PBR than UASB may be responsible for the lower hydrogen yield since their main metabolic products were lactic acid and ethanol, which will reduce the hydrogen yield [48]. Microbial diversity results supported the different performance of biohydrogen production through UASB and PBR, due to their differentiation of reaction mode.

\subsection{Side reaction of hydrogen fermentation: methanogenesis and homoacetogenesis}

The maximum hydrogen yields in UASB $(1.44 \pm 0.01 \mathrm{~mol} / \mathrm{mol}$ glucose $)$ and PBR $(0.67 \pm 0.06 \mathrm{~mol} / \mathrm{mol}$ glucose $)$ observed in this study were still lower than the expected maximum value ( $2 \mathrm{~mol} / \mathrm{mol}$ glucose [49]) for mesophilic hydrogen fermentation. The low hydrogen yield was partly caused by methanogenesis and homoacetogenesis. In order to understand the distribution of hydrogen gas, the quantification of two side biochemical reactions including methanogenesis and homoacetogenesis were conducted.

The methanogenesis was considered as the activity of hydrogenotrophic methanogens in this study due to the following reasons. Firstly, compared with the aceticlastic methanogens, hydrogenotrophic methanogens have a shorter generation time for easier survival from short HRT (12-24 h) [50]. Secondly, the final $\mathrm{pH}$ values in UASB and PBR were below 5 (Fig. 2D), which would inhibit aceticlastic methanogens rather than hydrogenotrophic methanogens due to the latter's high tolerance to acidic shock as previously observed [51]. As showed in the Table 3, the ratio of $\mathrm{H}_{2}$ methane $/ \mathrm{H}_{2}$ theoretical in PBR was higher than that of UASB, suggesting that PBR was more favorable for methanogenesis. 
The homoacetogenesis also had an effect on the decrease of the hydrogen yield, althrough heat pretreatment of seed sludge was conducted in this study, Luo et al. found that inhibition of homoacetogenesis during the long-term biohydrogen production was not dependent on the pretreatment of inoculum [25]. Illumina MiSeq sequencing results confirmed the existence of homoacetogenesis as there was a small amount of homoacetogenic microorganism Clostridium ljungdahlii in UASB and PBR, and might function as the conversion of hydrogen and carbon dioxide into acetate [52]. The quantification results showed (Table 3) that PBR had a higher value of $\mathrm{H}_{2}$ homo $/ \mathrm{H}_{2}$ theoretical, indicating more favorable conditions in PBR for homoacetogenesis.

\section{Conclusion}

This study demonstrated that the reaction mode significantly affected hydrogen fermentation and microbial diversity. UASB had a better performance than PBR for biohydrogen production with a maximal hydrogen production rate of $2.77 \pm 0.18 \mathrm{~L} / \mathrm{L} / \mathrm{d}$ and a hydrogen yield of $1.44 \pm 0.01 \mathrm{~mol} / \mathrm{mol}$ glucose, whereas PBR achieved $1.29 \pm 0.09$ $\mathrm{L} / \mathrm{L} / \mathrm{d}$ and $0.67 \pm 0.06 \mathrm{~mol} / \mathrm{mol}$ glucose, respectively. Illumina MiSeq sequencing results revealed much simple microbial diversity of UASB and PBR compared to the inoculum after 120 days' operation. PBR showed the lower proportion of hydrogen-producing microorganism Clostridium sp., higher distribution of ethanol and lactic acid producer, and its more favorable conditions for methanogenesis and homoacetogenesis.

\section{Acknowledgements}

This work was financially supported by the Natural Science Foundation of China (21106080), the Chinese Universities Scientific Fund (2012RC030), and National Key 
Technology Support Program of China (2014BAD02B03). The authors thank Jimson Watson (University of Illinois at Urbana-Champaign) for improving the manuscript.

\section{References:}

[1] Balat M. Potential importance of hydrogen as a future solution to environmental and transportation problems. Int J Hydrogen Energy 2008; 33: 4013-29.

[2] Dufour J, Serrano DP, Galvez JL, Moreno J, Garcia C. Life cycle assessment of processes for hydrogen production. Environmental feasibility and reduction of greenhouse gases emissions. Int J Hydrogen Energy 2009; 34: 1370-6.

[3] Argun H, Kargi F. Bio-hydrogen production by different operational modes of dark and photo-fermentation: An overview. Int J Hydrogen Energy 2011; 36: 7443-59.

[4] Show KY, Lee DJ, Chang JS. Bioreactor and process design for biohydrogen production. Bioresour Technol 2011; 102: 8524-33.

[5] Yu HQ, Zhu ZH, Hu WR, Zhang HS. Hydrogen production from rice winery wastewater in an upflow anaerobic reactor by using mixed anaerobic cultures. Int $\mathbf{J}$ Hydrogen Energy 2002; 27: 359-65.

[6] Chang FY, Lin CY. Biohydrogen production using an up-flow anaerobic sludge blanket reactor. Int J Hydrogen Energy 2004; 29: 33-9.

[7] Jung KW, Kim DH, Lee MY, Shin HS. Two-stage UASB reactor converting coffee drink manufacturing wastewater to hydrogen and methane. Int J Hydrogen Energy 2012; 37: 7473-81.

[8] Liu ZD, Lv FX, Zheng H, Zhang C, Wei F, Xing XH. Enhanced hydrogen production in a UASB reactor by retaining microbial consortium onto carbon nanotubes (CNTs). Int J Hydrogen Energy 2012; 37: 10619-26. 
[9] Castello E, Perna V, Wenzel J, Borzacconi L, Etchebehere C. Microbial community composition and reactor performance during hydrogen production in a UASB reactor fed with raw cheese whey inoculated with compost. Water Sci Technol 2011; 64: $2265-73$.

[10]Chang JS, Lee KS, Lin PJ. Biohydrogen production with fixed-bed bioreactors. Int J Hydrogen Energy 2002; 27: 1167-74.

[11]Júnior ADNF, Zaiat M, Gupta M, Elbeshbishy E, Hafez H, Nakhla G. Impact of organic loading rate on biohydrogen production in an up-flow anaerobic packed bed reactor (UAnPBR) . Bioresour Technol 2014; 164: 371-9.

[12]Perna V, Castello E, Wenzel J, Zampol C, Lima DMF, Borzacconi L, Varesche MB, Zaiat M, Etchebehere C. Hydrogen production in an upflow anaerobic packed bed reactor used to treat cheese whey. Int J Hydrogen Energy 2013; 38: 54-62.

[13]Peixoto G, Saavedra NK, Varesche MBA, Zaiat M. Hydrogen production from softdrink wastewater in an upflow anaerobic packed-bed reactor. Int J Hydrogen Energy 2011; 36: 8953-66.

[14]Júnior ADNF, Wenzel J, Etchebehere C, Zaiat M. Effect of organic loading rate on hydrogen production from sugarcane vinasse in thermophilic acidogenic packed bed reactors. Int J Hydrogen Energy 2014; 39: 16852-62.

[15]Lima DMF, Moreira WK, Zaiat M. Comparison of the use of sucrose and glucose as a substrate for hydrogen production in an upflow anaerobic fixed-bed reactor. Int $\mathbf{J}$ Hydrogen Energy 2013; 38: 15074-83.

[16]Lima DMF, Zaiat M. The influence of the degree of back-mixing on hydrogen production in an anaerobic fixed-bed reactor. Int J Hydrogen Energy 2012; 37: 96305. 
[17]Lee DJ, Show KY, Su A. Dark fermentation on biohydrogen production: Pure culture. Bioresour Technol 2011; 102: 8393 - 402.

[18]Zhang ZP, Show KY, Tay JH, Liang DT, Lee DJ. Biohydrogen production with anaerobic fluidized bed reactors-A comparison of biofilm-based and granule-based systems. Int J Hydrogen Energy 2008; 33: 1559-64.

[19]Alzate-Gaviria LM, Sebastian PJ, Pérez-Hernández A, Eapen D. Comparison of two anaerobic systems for hydrogen production from the organic fraction of municipal solid waste and synthetic wastewater. Int J Hydrogen Energy 2007; 32: 3141-6.

[20]Wang JL, Wan W. Comparison of different pretreatment methods for enriching hydrogen-producing bacteria from digested sludge. Int J Hydrogen Energy 2008; 33: 2934-41.

[21]Lin CY, Lay CH. Carbon/nitrogen-ratio effect on fermentative hydrogen production by mixed microflora. Int J Hydrogen Energy 2004; 29: 41-5.

[22] Mohan SV, Chiranjeevi P, Mohanakrishna G. A rapid and simple protocol for evaluating biohydrogen production potential (BHP) of wastewater with simultaneous process optimization. Int J Hydrogen Energy 2012; 37: 3130-41.

[23]APHA, AWWA, WEF. Standard methods for the examination of water and wastewater. 20th ed. Washington, DC, USA: American Public Health Association; 1998.

[24] Kumaraswamy R, Amha YM, Anwar MZ, Henschel A, Rodriguez J, Ahmad F. Molecular analysis for screening human bacterial pathogens in municipal wastewater treatment and reuse. Environ Sci Technol 2014; 48: 11610-9.

[25]Luo G, Karakashev D, Xie L, Zhou Q, Angelidaki I. Long-term effect of inoculum pretreatment on fermentative hydrogen production by repeated batch cultivations: 
Homoacetogenesis and methanogenesis as competitors to hydrogen production. Biotechnol Bioeng 2011; 108: 1816-27.

[26] Arooj MF, Han SK, Kim SH, Kim DH, Shin HS. Continuous biohydrogen production in a CSTR using starch as a substrate. Int J Hydrogen Energy 2008; 33: 3289-94.

[27]Ginkel SV, Sung S, Lay JJ. Biohydrogen production as a function of $\mathrm{pH}$ and substrate concentration. Environ Sci Technol 2001; 35: 4726-30.

[28]Li CL, Fang HHP. Fermentative hydrogen production from wastewater and solid wastes by mixed cultures. Crit Rev Environ Sci Technol 2007; 37: 1-39.

[29]Penteado ED, Lazaro CZ, Sakamoto IK, Zaiat M. Influence of seed sludge and pretreatment method on hydrogen production in packed-bed anaerobic reactors. Int $\mathbf{J}$ Hydrogen Energy 2013; 38: 6137-45.

[30]Hawkes FR, Dinsdale R, Hawkes DL, Hussy I. Sustainable fermentative hydrogen production: challenges for process optimisation. Int J Hydrogen Energy 2002; 27:1339-47.

[31]Kyazze G, Guwy AI, Premier GC. Performance characteristics of a two-stage dark fermentative system producing hydrogen and methane continuously. Biotechnol Bioeng 2007; 97: 759-70.

[32]Luo G, Xie L, Zhou Q, Angelidaki I. Enhancement of bioenergy production from organic wastes by two-stage anaerobic hydrogen and methane production process. Bioresour Technol 2011; 102: 8700-6.

[33]Liu Z, Zhang C, Wang L, He J, Li B, Zhang Y, Xing XH. Effects of furan derivatives on biohydrogen fermentation from wet steam-exploded cornstalk and its microbial community. Bioresour Technol 2015; 175: 152-9. 
[34]Babu VL, Mohan SV, Sarma PN. Influence of reactor configuration on fermentative hydrogen production during wastewater treatment. Int J Hydrogen Energy 2009; 34: 3305-12.

[35]Mohan SV, Bhaskar YV, Sarma PN. Biohydrogen production from chemical wastewater treatment in biofilm configured reactor operated in periodic discontinuous batch mode by selectively enriched anaerobic mixed consortia. Water Res 2007; 41: 2652-64.

[36]Mohan SV, Mohanakrishna G, Ramanaiah SV, Sarma PN. Simultaneous biohydrogen production and wastewater treatment in biofilm configured anaerobic periodic discontinuous batch reactor using distillery wastewater. Int J Hydrogen Energy 2008; 33: 550-8.

[37] Keskin T, Giusti L, Azbar N. Continuous biohydrogen production in immobilized biofilm system versus suspended cell culture. Int J Hydrogen Energy 2012; 37: 141824.

[38]Liu Y, Xu HL, Yang SF, Tay JH. Mechanisms and models for anaerobic granulation in upflow anaerobic sludge blanket reactor. Water Res 2003; 37: 661-73.

[39]Ning YY, Wang SF, Jin DW, Harada H, Shi XY. Formation of hydrogen-producing granules and microbial community analysis in a UASB reactor. Renewable Energy 2013; 53: 12-17.

[40]Elsharnouby O, Hafez H, Nakhla G, Naggar MH. A critical literature review on biohydrogen production by pure cultures. Int J Hydrogen Energy 2013; 38: 4945-66.

[41]Lin PJ, Whang LM, Wu YR, Ren WJ, Hsiao CJ, Li SL, Chang JS. Biological hydrogen production of the genus Clostridium: Metabolic study and mathematical model simulation. Int J Hydrogen Energy 2007; 32: 1728-35. 
[42] Veeravalli SS, Chaganti SR, Lalman JA, Heath DD. Optimizing hydrogen production from a switchgrass steam exploded liquor using a mixed anaerobic culture in an upflow anaerobic sludge blanket reactor. Int J Hydrogen Energy 2014; 39: 3160-75.

[43]Guo WQ, Ren NQ, Wang XJ, Xiang WS, Ding J, You Y. Optimization of culture conditions for hydrogen production by Ethanoligenens harbinense B49 using response surface methodology. Bioresour Technol 2009; 100: 1192-6.

[44]Robert H, Gabriel V, Fontagné-Faucher C. Biodiversity of lactic acid bacteria in French wheat sourdough as determined by molecular characterization using speciesspecific PCR. Int J Food Microbiol 2009; 135: 53-59.

[45] Ohashi R, Yamamoto T, Suzuki T. Continuous production of lactic acid from molasses by perfusion culture of Lactococcus lactis using a stirred ceramic membrane reactor. J Biosci Bioeng 1999; 87: 647-54.

[46]Chojnacka A, Blaszczyk MK, Szczesny P, Nowak K, Suminska M, Tomczyk-Zak K, Zielenkiewicz U, Sikora A. Comparative analysis of hydrogen-producing bacterial biofilms and granular sludge formed in continuous cultures of fermentative bacteria. Bioresour Technol 2011; 102: 10057-64.

[47]Fang HHP, Zhang T, Liu H. Microbial diversity of a mesophilic hydrogen-producing sludge. Appl Microbiol Biotechnol 2002; 58: 112-8.

[48]Hawkes FR, Hussy I, Kyazze G, Dinsdale R, Hawkes D. Continuous dark fermentative hydrogen production by mesophilic microflora: Principles and progress. Int J Hydrogen Energy 2007; 32: 172-84.

[49]Lee H, Salerno MB, Rittmann BE. Thermodynamic evaluation on $\mathrm{H}_{2}$ production in glucose fermentation. Environ Sci Technol 2008; 42: 2401-7. 
[50]Pavlostathis SG. Kinetics of anaerobic treatment: A critical review. Crit Rev Environ Control 1991; 21: 411-90.

[51]Kim IS, Hwang MH, Jang NJ, Hyun S, Lee S. Effect of low pH on the activity of hydrogen utilizing methanogen in bio-hydrogen process. Int J Hydrogen Energy 2004; 29: 1133-40.

[52]Drake H, Kusel K, Matthies C. Ecological consequences of the phylogenetic and physiological diversities of acetogens. Antonie van Leeuwenhoek 2002; 81: 203-13. 


\section{Figure captions:}

Fig. 1 Schematic description of the UASB (A) and PBR (B) for continuous biohydrogen production.

Fig.2. Performance of UASB and PBR for biohydrogen production. OLR (A), HRT (B), initial $\mathrm{pH}(\mathrm{C})$, final $\mathrm{pH}(\mathrm{D})$, gas composition $(\mathrm{E})$, gas production rate $(\mathrm{F})$, COD removal rate (G) and VFAs yields (H, I).

Fig. 3 The relationships between gas yields and OLR.

Fig. 4 SEM images of inoculum (A, D), granules in UASB (B, E) and biofilms in PBR (C, F).

Fig. 5 Venn chart of the inoculum, microbial consortia in granules in UASB and biofilms in PBR. The numbers represents OTUs (operational taxonomic units). The number of OTUs and their overlaps among cycles illustrate the logical relations between microbial samples. Fig. 6 Taxonomic classification bacterial communities of inoculum, UASB and PBR at the phyla (A), families (B) and genera (C) levels through Illumina Miseq sequencing. 
Table 1 Diversity analysis of the microbial community for clustering at $97 \%$ identity.

\begin{tabular}{lllll}
\hline Sample & Chao & Shannon & Simpson & ACE \\
\hline Inoculum & 416 & 3.57 & 0.0829 & 401 \\
UASB & 65 & 1.48 & 0.4013 & 137 \\
PBR & 105 & 2.29 & 0.1879 & 106 \\
\hline
\end{tabular}


Table 2 Representative microorganisms involved in biohydrogen production and their fermentation products

\begin{tabular}{llll}
\hline Microorganisms & Family & Fermentation products & Reference \\
\hline Clostridium $\mathrm{sp}$. & Clostridiaceae & $\mathrm{H}_{2}$, butyrate, acetate & {$[41]$} \\
Weissella $\mathrm{sp}$. & Leuconostocaceae & lactate, acetate, ethanol & {$[46]$} \\
Ethanoligenens $\mathrm{sp}$. & Ruminococcaceae & $\mathrm{H}_{2}$, ethanol, acetate & {$[42,43]$} \\
Ruminococcaceae Incertae & Ruminococcaceae & $\mathrm{H}_{2}$, ethanol, acetate & {$[42,43]$} \\
Sedis $\mathrm{sp}$. & & & \\
Lactococcu $\mathrm{sp}$. & Streptococcaceae & lactate & {$[47]$} \\
\hline
\end{tabular}


Table 3 Quantification for methanogenesis and homoacetogenesis in UASB and PBR under an OLR of $15.36 \mathrm{~g}$ COD/L/L

\begin{tabular}{llll}
\hline & $\mathrm{Ac}_{\text {homo }} / \mathrm{Ac}_{\text {total }}(\%)$ & $\mathrm{H}_{2 \text { methane }} / \mathrm{H}_{2 \text { theoretical }}(\%)$ & $\mathrm{H}_{2 \text { homo }} / \mathrm{H}_{2 \text { theoretic }}(\%)$ \\
\hline UASB & $1.5 \pm 4.2$ & $5.2 \pm 3.8$ & $1.3 \pm 0.5$ \\
PBR & $11.1 \pm 3.4$ & $49.4 \pm 6.0$ & $12.4 \pm 0.8$ \\
\hline
\end{tabular}


Fig. 1 Schematic description of the UASB (A) and PBR (B) for continuous biohydrogen production.

A

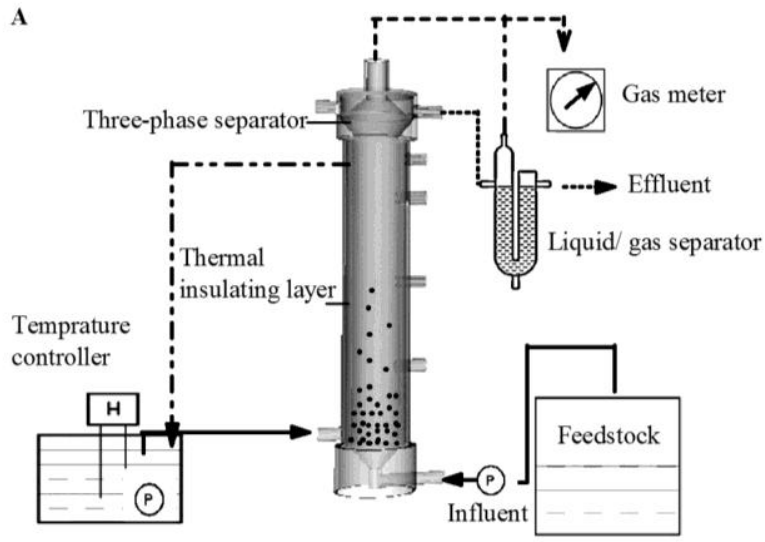

UASB

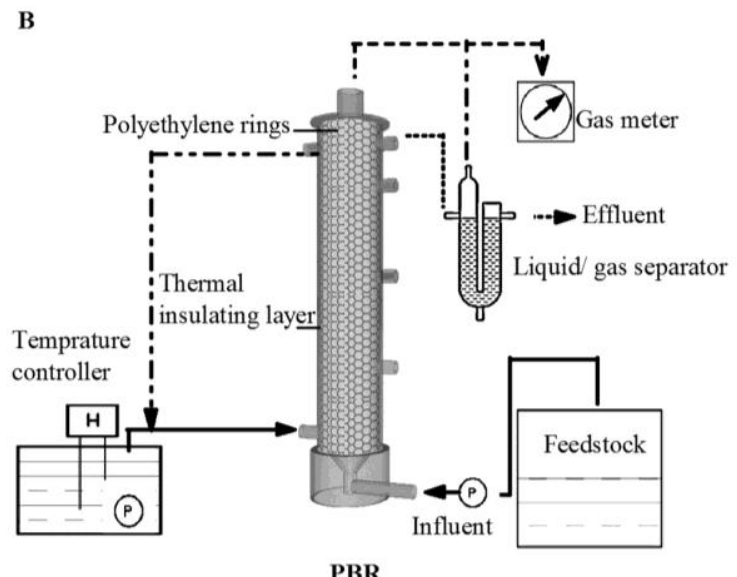


Fig.2. Performance of UASB and PBR for biohydrogen production. OLR (A), HRT (B), initial $\mathrm{pH}(\mathrm{C})$, final $\mathrm{pH}(\mathrm{D})$, gas composition (E), gas production rate $(\mathrm{F}), \mathrm{COD}$ removal rate (G) and VFAs yields (H, I).

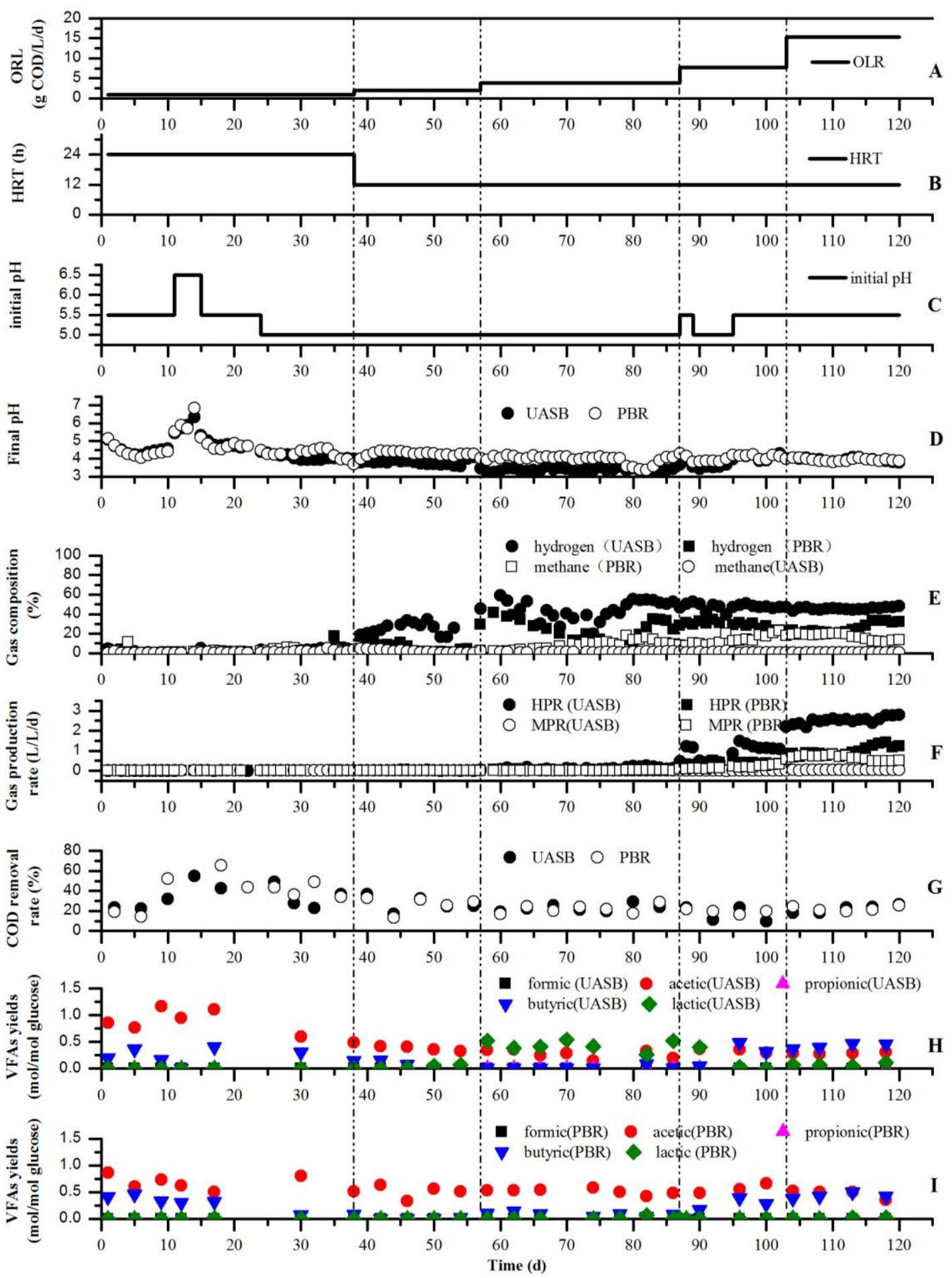


Fig. 3 The relationships between gas yields and OLR.

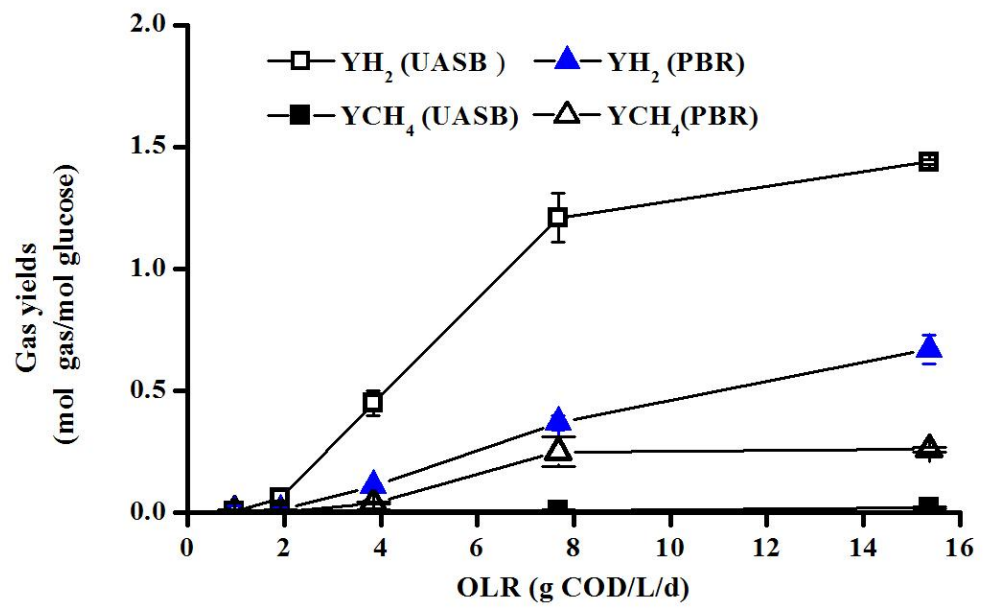


Fig. 4 SEM images of inoculum (A, D), granules in UASB (B, E) and biofilms in PBR $(\mathrm{C}, \mathrm{F})$.

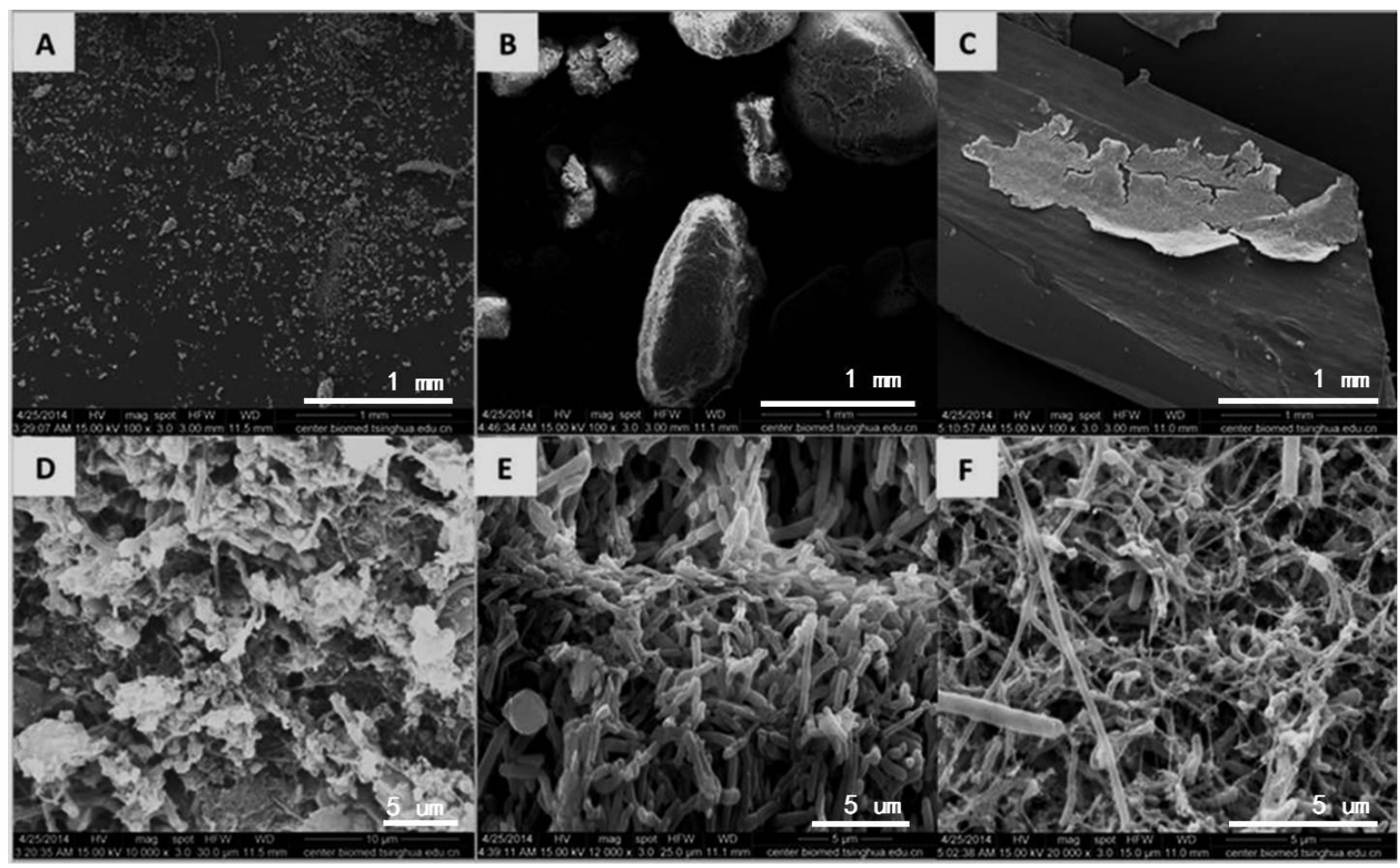


Fig. 5 Venn chart of the inoculum, microbial consortia in granules in UASB and biofilms in PBR. The numbers represents OTUs (operational taxonomic units). The number of OTUs and their overlaps among cycles illustrate the logical relations between microbial samples.

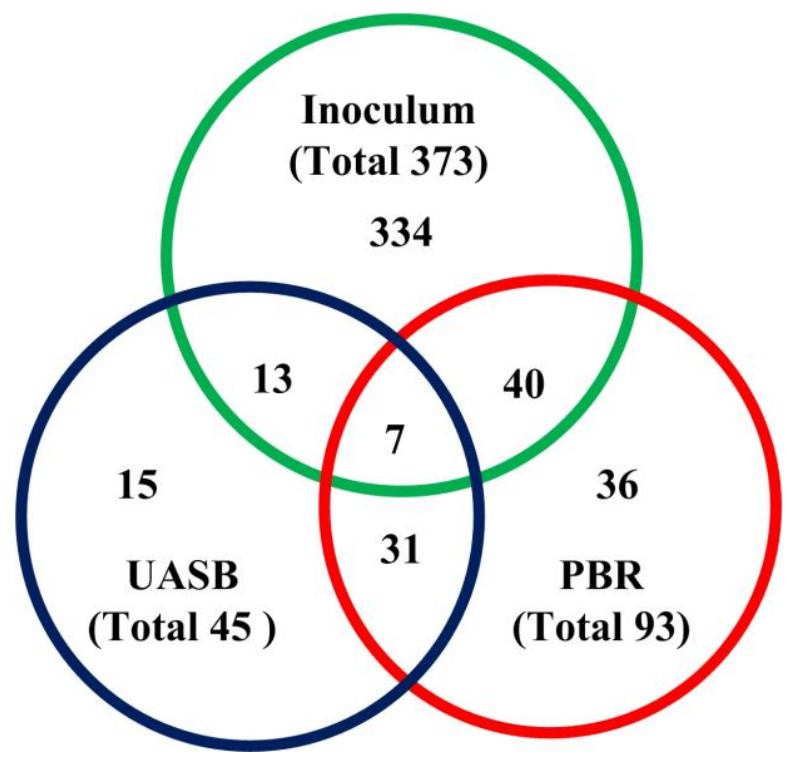


Fig. 6 Taxonomic classification bacterial communities of inoculum, UASB and PBR at the phyla (A), families (B) and genera (C) levels through Illumina Miseq sequencing. Phyla, families and genera less than $1 \%$ of total composition in all three libraries were classified as "others".

A Bacterial phyla

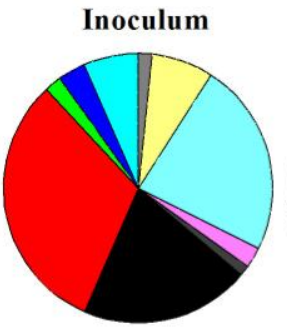

B Bacterial families
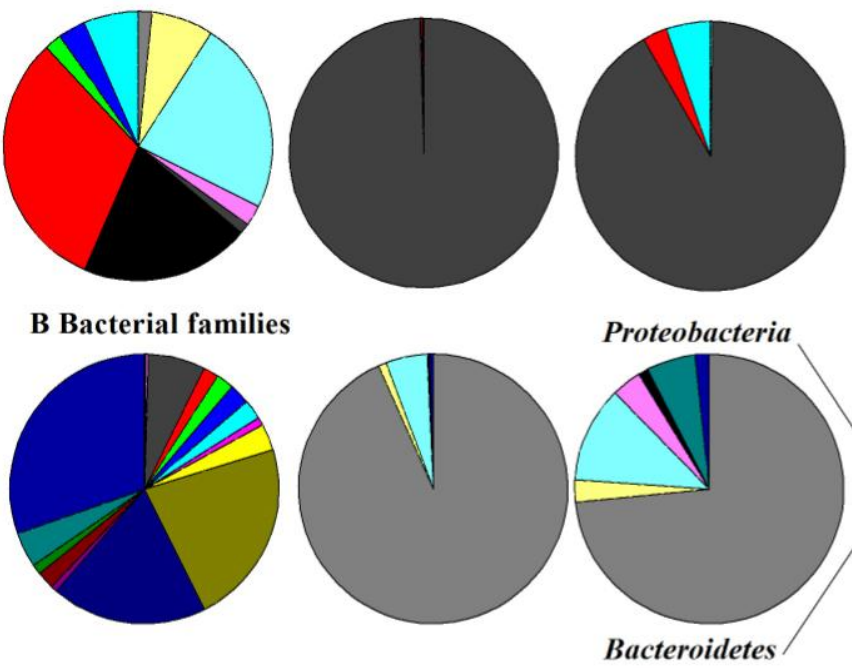

Actinobacteria

Bacteroidetes

Chloroflexi

Firmicutes

Planctomycetes

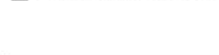

Firmicutes

\begin{tabular}{|c|c|}
\hline $\begin{array}{l}\text { Clostridiaceae } \\
\text { Ruminococcaceae }\end{array}$ & Leuconostocaceae \\
\hline Comamonadaceae & Enterobacteriaceae \\
\hline Hydrogenophilaceae & Rhodobacteraceae \\
\hline Rhodocyclaceae & Xanthomonadaceae \\
\hline Porphyromonadaceae & Rikenellaceae \\
\hline Anaerolineaceae & Spirochaetaceae \\
\hline Microbacteriaceae & Thermotogaceae \\
\hline $\begin{array}{l}\text { Planctomycetaceae } \\
\text { Others }\end{array}$ & Unclassified \\
\hline
\end{tabular}

C Bacterial genera

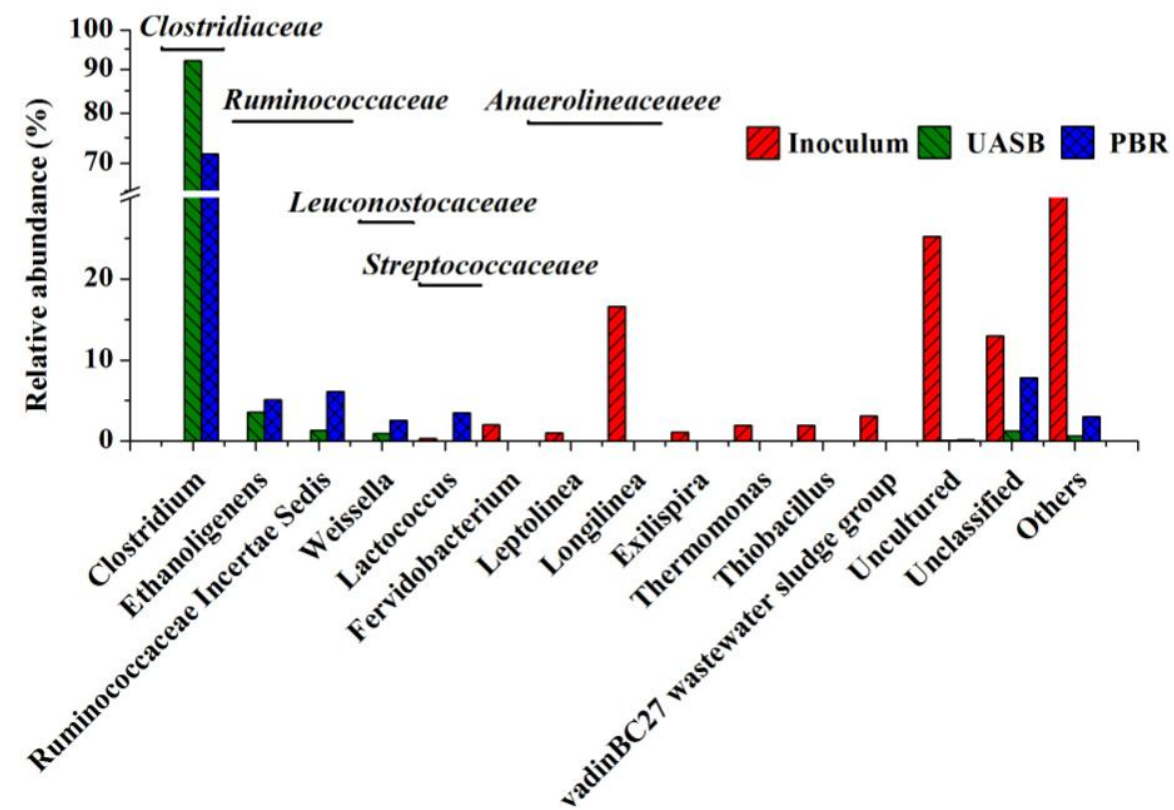

